\title{
The pharmacological cost of COPD during Greek economic crisis
}

\author{
This article was published in the following Dove Press journal: \\ International Journal of COPD \\ 31 January 2017 \\ Number of times this article has been viewed
}

\section{Eirini Stafyla' \\ Theodora Kerenidi' \\ Irini Gerogianni' \\ Mary Geitona ${ }^{2}$ \\ Zoe Daniil' \\ Konstantinos I \\ Gourgoulianis'}

'Respiratory Medicine Department, University of Thessaly School of Medicine, University Hospital of Larissa, Larissa, ${ }^{2}$ Department of Social Policy, University of Peloponnese, Korithos, Greece
Correspondence: Eirini Stafyla Respiratory Medicine Department, University Hospital of Larissa, Mezourlo, 4I II 0 Larissa, Greece

Tel +3024 I350 2896

Fax +3024 I350 I563

Email eirinistaf@hotmail.com
Introduction: The economic crisis in Greece has substantially affected patients with COPD. The reduction of disposable income has its consequences on patients' ability to afford their medication. The aim of the study is to evaluate the cost of treatment for patients with COPD and the influence of the financial crisis to the patients.

Methods: Data were collected from 189 patients (male: 178 , mean age: $70.1 \pm 8.4$ ) who visited the outpatient department of University Hospital of Larissa in 2014 and 2015. The pharmacological cost of treatment was calculated based on national pharmaceutical formulary prices.

Results: COPD patients were classified into four stages according to Global Initiative for Chronic Obstructive Lung Disease (GOLD): $7.4 \%$ were in stage I, $43.4 \%$ in stage II, $34.4 \%$ in stage III, and $14.8 \%$ in stage IV. Patients were graded as per GOLD as follows: $18 \%$ as grade $\mathrm{A}, 14.3 \%$ as $\mathrm{B}, 23.3 \%$ as $\mathrm{C}$, and $44.4 \%$ as D. The annual cost of COPD maintenance treatment per patient was $€ 952.92$ ( \pm 398.01$)$, of which $€ 239.91$ were patients' expenses. The annual treatment cost for stable disease ranged from $€ 615.44$ to $€ 1302.03$ depending on disease stages (GOLD stages I-IV) and from $€ 715.01$ to $€ 1101.05$ depending on GOLD grades (grades A-D). The cost of maintenance medication was statistically and significantly higher for patients with advanced disease (GOLD stages III-IV) and for patients at high risk (GOLD grades $\mathrm{C}-\mathrm{D}[P=0.000]$ ).

Conclusion: The pharmacological cost of treatment for COPD patients seems to be considerably high, in all disease stages. As the average income is decreased, patients face difficulties to afford inhaled medication.

Keywords: COPD, maintenance treatment, pharmacological cost, economic crisis

\section{Introduction}

The global economic crisis has severely affected many European countries since $2008 .{ }^{1}$ Greece is one of the countries that is dealing with one of the most severe financial crisis in its history, which has had disheartening effects in many aspects of life. ${ }^{2}$ Greek populations' average income was decreased due to reductions in salaries, pensions, and benefits and surge in unemployment rates. ${ }^{1}$ At the same time, citizens had to face huge changes and cuts in National Health Care system. Co-payments for medicine and services were increased, while access to health care was undermined. ${ }^{1,3}$

Unmet health care needs due to financial reasons have increased during the past few years. ${ }^{4}$ The barriers in access to health care services particularly affected chronic patients, who constitute a vulnerable group of the population with increased needs for health care..$^{5}$ The hardest blow for chronic patients during crisis was the increase at patients' co-payments percentage for medication from $10 \%$ to $25 \%$. As a result, medication for chronic conditions, such as COPD, became unaffordable for many patients. 
COPD is a major cause of morbidity and mortality worldwide. It is the fourth leading cause of death, ${ }^{6}$ and according to WHO estimates, 65 million people suffer from the disease. ${ }^{7}$ In Greece, the prevalence of COPD is estimated to be around $8.4 \%$ in those aged $>35$ years with a smoking history of $>100$ cigarettes per lifetime, meaning that approximately 700,000 people suffer from the disease. ${ }^{8}$ Moreover, COPD usually coexists with other diseases that may have significant impact on prognosis. ${ }^{6}$

COPD is associated with increased costs for each national health system. In 2010, the economic burden of COPD in the United States was projected to be approximately US\$49.9 billion, ${ }^{9}$ while in Europe, the cost of COPD was estimated to be $€ 48.4$ billion in 2011 , of which $€ 23.3$ billion was referred to direct health care expenditures. ${ }^{10}$ In Greece, the total cost of COPD has never been calculated, but the cost of severe exacerbations was estimated as $€ 1711$. $^{11}$

The economic crisis has seriously affected patients with COPD. Chronic use of inhaled medication is of paramount importance for COPD patients in order to reduce their symptoms and prevent exacerbations. However, reduction of disposable income has its consequences in patients' ability to afford for their medication. The aim of the present study is to evaluate the cost of maintenance medication for patients with COPD and the impact of the financial crisis on COPD patients.

\section{Materials and methods}

The study sample consisted of 189 patients randomly selected from the pulmonology outpatient department of University Hospital of Larissa between January 2014 and December 2015. Eligible patients were those aged over 40 years and those who had been diagnosed with COPD at least 1 year prior to their visit. Spirometry test was also required to confirm the diagnosis of COPD (post-bronchodilator forced expiratory volume in 1 second $\left[\mathrm{FEV}_{1}\right]$ /forced vital capacity $[\mathrm{FVC}]<0.70) .{ }^{6}$ The study was approved by the University of Thessaly and the University Hospital of Larissa ethics committees and written informed consent was obtained from the participants.

COPD patients were classified into four stages of disease severity (based on $\mathrm{FEV}_{1}$ ) and then into four groups according to guidelines of the Global Initiative for Chronic Obstructive Lung Disease (GOLD).

Patient's maintenance medication during the last years was recorded using brand names. The pharmacological cost was calculated based on national pharmaceutical formulary prices (cost base year 2014). Patients' expenses for the treatment were calculated separately, according to the prices set by the Ministry of Health. Specifically, social security funds cover $75 \%$ of the price of the generic pharmaceutical formulation for all drugs related with COPD and 90\% for some retirees receiving very low pensions.

Data were expressed as mean \pm standard deviation for continuous variables and as percentages when reporting categorical variables. Independent samples $t$-test for independent samples was also performed, and cutoff point of $P$-value $<0.05$ was used to mark statistical significance. Statistical analysis of the data was performed using Statistical Package for the Social Sciences version 20 (IBM Corp., Armonk, NY, USA).

\section{Results}

Out of 189 patients, $178(94.2 \%)$ were men, with mean age 70.1 years. The majority of COPD patients were retired (81\%) and ex-smokers (58.7\%). Moreover, $87.7 \%$ of the participants report at least one comorbid condition for which they receive medication. The demographic and clinical characteristics of COPD patients, as well as their maintenance medications, are presented in Table 1 .

According to GOLD classification based on $\mathrm{FEV}_{1}, 49.2 \%$ of COPD patients had already severe or very severe disease (stages III-IV), while 67.7\% were categorized as "high-risk" groups (grades $\mathrm{C}-\mathrm{D}$ ). The distribution of patients by GOLD stages and grades is shown in Tables 2 and 3.

The total annual cost of COPD maintenance treatment per patient was $€ 952.92$ ( $\mathrm{SD}=398.01$ ), of which $€ 239.91$ correspond to patients' expenses. The annual treatment cost for stable disease ranges from $€ 615.44$ to $€ 1302.03$ depending on disease stages (I-IV) and from $€ 715.01$ to $€ 1101.05$ depending on GOLD groups (A-D). The cost of treatment is depicted extensively in Tables 4 and 5. The cost of COPD medication was significantly higher for patients with severe and very severe disease (stages III-IV $[P=0.000]$ ) and for patients of "high-risk" groups (grades $\mathrm{C}-\mathrm{D}[P=0.000]$ ).

\section{Discussion}

Our study showed that the pharmacological cost of treatment seems to be considerably high for patients with COPD. The mean annual cost of treatment for each COPD patient is $€ 952.92$, of which €239.91 are patients' expenses. Although the cost of inhaled medication rises with disease progression, the cost in all stages of COPD is pretty high.

In the present study, the cost of treatment was increased by disease progression according to GOLD classification stages (I-IV) and grades (A-D). The cost of maintenance medication was significantly higher for those with severe or 
Table I Demographic and clinical characteristics of COPD patients $(n=189)$

\begin{tabular}{|c|c|}
\hline Characteristics & Results \\
\hline Age (mean [SD]) & $70.1(8.4)$ \\
\hline Gender: male ( $\mathrm{n}[\%])$ & I $78(94.2)$ \\
\hline BMI (mean [SD]) & $29(6.1)$ \\
\hline Occupational exposure (n [\%]) & $22(11.6)$ \\
\hline \multicolumn{2}{|l|}{ Working status (n [\%]) } \\
\hline Retired & $153(8 \mid)$ \\
\hline Working & $26(13.8)$ \\
\hline Unemployed & $10(5.3)$ \\
\hline \multicolumn{2}{|l|}{ Area of residence ( $[\%]$ ) } \\
\hline Urban & $82(43.4)$ \\
\hline Suburban & $39(20.6)$ \\
\hline Rural & $68(36)$ \\
\hline \multicolumn{2}{|l|}{ Smoking habit (n [\%]) } \\
\hline Current smoker & $73(38.6)$ \\
\hline Ex-smoker & III (58.7) \\
\hline Nonsmoker & $5(2.6)$ \\
\hline Pack-years (mean [SD]) & $82.8(38.2)$ \\
\hline Years with COPD (mean [SD]) & $7.6(5.5)$ \\
\hline LTOT (n [\%]) & $52(27.5)$ \\
\hline NIV (n [\%]) & $4 I(2 I .7)$ \\
\hline $\mathrm{FEV}, \%$ (mean [SD]) & $5 I .5(18.8)$ \\
\hline \multicolumn{2}{|l|}{ Frequent comorbidities (n [\%]) } \\
\hline Hypertension & $92(48.7)$ \\
\hline Diabetes & $40(2 \mid .2)$ \\
\hline Coronary heart disease & $37(19.6)$ \\
\hline Hyperlipidemia & $34(18)$ \\
\hline Prostate diseases & $30(15.9)$ \\
\hline Chronic heart failure & $24(12.7)$ \\
\hline \multicolumn{2}{|l|}{ Maintenance medication (n [\%]) } \\
\hline LAMA & $36(19)$ \\
\hline LABA & $4(2.1)$ \\
\hline LAMA + LABA combination & $16(8.5)$ \\
\hline LABA + ICS combination & $2 I(I I . I)$ \\
\hline LAMA + LABA + ICS combination & $94(49.7)$ \\
\hline SAMA & I (0.5) \\
\hline SAMA + SABA combination & $\mathrm{I}(0.5)$ \\
\hline SAMA + SABA + ICS combination & $16(8.5)$ \\
\hline PDE4 inhibitor & $12(6.3)$ \\
\hline Xanthines & $3(1.6)$ \\
\hline
\end{tabular}

Abbreviations: SD, standard deviation; BMI, body mass index; LTOT, long-term oxygen therapy; NIV, noninvasive ventilation; $\mathrm{FEV}_{1}$, forced expiratory volume in I second; LAMA, long-acting muscarinic antagonist; LABA, long-acting $\beta 2$-agonist; ICS, inhaled corticosteroid; SAMA, short-acting muscarinic antagonist; SABA, shortacting $\beta 2$-agonist; PDE4 inhibitor, phosphodiesterase-4 inhibitor.

Table 2 Classification of patients in GOLD stages based on FEV , $(n=189)$

\begin{tabular}{ll}
\hline & Results (n [\%]) \\
\hline Stage I & $14(7.4)$ \\
Stage II & $82(43.4)$ \\
Stage III & $65(34.4)$ \\
Stage IV & $28(14.8)$ \\
\hline
\end{tabular}

Abbreviations: GOLD, Global Initiative for Chronic Obstructive Lung Disease; $\mathrm{FEV}_{1}$, forced expiratory volume in I second.
Table 3 Classification of patients according to GOLD grades $(n=189)$

\begin{tabular}{ll}
\hline & Results (n [\%]) \\
\hline Grade A & $34(18)$ \\
Grade B & $27(14.3)$ \\
Grade C & $44(23.3)$ \\
Grade D & $84(44.4)$ \\
\hline
\end{tabular}

Abbreviation: GOLD, Global Initiative for Chronic Obstructive Lung Disease.

very severe disease (GOLD stages III-IV) and for those who were categorized as high-risk groups (GOLD grades $\mathrm{C}-\mathrm{D}$ $[P=0.000$ for both]). Similar results were reported in Boland et al's ${ }^{12}$ study, which showed that GOLD grades (A-D) were strongly related with the cost of the disease. Specifically, total health care costs were significantly increased with increasing GOLD grades (A-D). The study showed that health care costs per patient was higher in GOLD grade B $(72 \%)$, grade $\mathrm{C}(74 \%)$, and grade $\mathrm{D}(131 \%)$ patients than in grade $\mathrm{A}$ patients. Costs of patients with grade B were similar to those with grade $\mathrm{C}$, but significantly lower than those with grade D. Similar results were also reported for GOLD stages.

In our study, two out of three patients were categorized as high-risk groups (grades $\mathrm{C}-\mathrm{D}$ ). Similar results were reported in our previous study, in which more than $60 \%$ of the patients were assessed as high-risk groups. ${ }^{13}$ All these patients are in high risk of exacerbations and possible hospitalizations, and combinations of therapies are required to provide symptom control and to prevent possible complications. Therefore, as "high-risk" patient percentage is pretty high, it is obvious why almost half of the patients were receiving a triple combination therapy as maintenance medication (long-acting muscarinic antagonist [LAMA] + long-acting $\beta 2$-agonist [LABA] + inhaled corticosteroid [ICS]). This combination therapy is the reason for the large increase of medication cost in this group of patients.

In times of economic crisis, that the basic pension is $€ 486.84$ per month for unmarried person and $€ 523.37$ per month for a married person, ${ }^{14} \mathrm{COPD}$ patients - who are retirees $(81 \%)$ - have to spend a significant proportion of their pension only for the drugs of one disease. From this, and along with the fact that most of the patients with COPD suffer from other comorbidities at the same time ( $87.7 \%$ in our study), it is obvious that patients struggle to afford their medication.

Patients now spend a significantly larger percentage of their monthly pension to afford their medication compared to the years before crisis. Data was not available for basic pensions at the beginning of the crisis, where pensions between social security funds of pensioners differed and/or different benefits were received. However, the 
Table 4 Pharmacological cost of treatment per patient according to GOLD stage of disease (based on FEV $)$ ), in Euros (€)

\begin{tabular}{|c|c|c|c|c|}
\hline Cost of treatment & $\begin{array}{l}\text { Mild COPD } \\
\text { (Stage I) }\end{array}$ & $\begin{array}{l}\text { Moderate COPD } \\
\text { (Stage II) }\end{array}$ & $\begin{array}{l}\text { Severe COPD } \\
\text { (Stage III) }\end{array}$ & $\begin{array}{l}\text { Very severe COPD } \\
\text { (Stage IV) }\end{array}$ \\
\hline \multicolumn{5}{|c|}{ Cost of treatment per month (mean [SD]) } \\
\hline For patients & $12.53(7.16)$ & |6.7| (7.52) & $23.72(17.43)$ & $29.23(10.86)$ \\
\hline For social security funds & $38.76(12.60)$ & $51.05(19.94)$ & $65.87(23.62)$ & $79.27(24.80)$ \\
\hline Total monthly cost & $51.29(18.76)$ & $67.79(26.5 \mathrm{I})$ & $87.64(31.07)$ & $108.5(35.04)$ \\
\hline \multicolumn{5}{|c|}{ Cost of treatment per year (mean [SD]) } \\
\hline For patients & $150.30(85.97)$ & $200.53(90.27)$ & $261.14(111.64)$ & $350.79(130.34)$ \\
\hline For social security funds & $465.14(151.23)$ & $612.55(239.22)$ & $790.49(283.46)$ & $951.24(297.59)$ \\
\hline Total annual cost & $615.44(225.12)$ & $813.08(318.33)$ & $\mathrm{I}, 05 \mathrm{I} .63(372.87)$ & I,302.03 (420.45) \\
\hline
\end{tabular}

Abbreviations: GOLD, Global Initiative for Chronic Obstructive Lung Disease; FEV , forced expiratory volume in I second; SD, standard deviation.

Organization for Economic Co-operation and Development (OECD) mentions that before crisis (2007), pensioners had received 14 monthly payments and supplementary pensions,${ }^{15}$ while in 2015 monthly payments were reduced to 12 , and supplementary pensions were cut. ${ }^{14}$ Moreover, at the beginning of the financial crisis, the cost share for patients with chronic diseases (such as COPD) was $10 \%$, while during the years of crisis the cost-sharing percentage was increased to $25 \%$. Considering that pensioners' actual income was also decreased due to the increase of taxes, we estimate that the amount that patients spend for their medication is remarkable, as now the amount represents proportionately a higher percentage of their income, compared to times before crisis.

Following the large income decrease caused by financial crisis, there were many patients who reported decrease in spending for various expenditure categories, in order to maintain their ability to finance their health care needs. However, despite the fact that health seems to be the last expenditure category that a chronic patient would be willing to decrease his spending for, 1 out of 5 patients was forced to reduce spending for his health condition, according to a recent study in Greece. ${ }^{16}$ Especially for COPD patients, Skroumpelos et al's ${ }^{16}$ study reports that patients with COPD report significant decrease in spending for physician visits (17.5\%), examinations (14.7\%), and COPD drugs (5.8\%).

Out-of-pocket costs for medication also affect adherence to treatment. The patients' expenses for the treatment may lead to reduced use of essential medication, resulting in serious adverse events and increased costs due to disease complications. ${ }^{17}$ Previous data published from our group showed that in Greece adherence with treatment remains significantly low. ${ }^{18}$ High rates of non-adherence were also reported in GOLDEN study, as only $55 \%$ of the patients reported never forgetting to take their medication. ${ }^{19}$ Tsiligianni et al's ${ }^{3}$ study, on 288 chronic patients, reports that the majority of patients have lowered the doses of their medication by themselves as they were not able to afford the cost. Specifically, patients with COPD or asthma had stopped their medication completely, decreased dosages, or used similar medications they had in the past (46.42\%). This non-adherence to inhalation treatment could have significant long-term consequences for patients with respiratory diseases, while for patients suffering also from comorbid conditions the cost-related non-adherence problems are even greater. ${ }^{20}$

Shrinking incomes have led patients to cut down on their visits to doctors. ${ }^{21}$ A significant proportion of patients, who cannot afford to pay for physician visits, usually receive medication prescribed months or years ago. These patients

Table 5 Pharmacological cost of treatment per patient according to GOLD grades, in Euros (€)

\begin{tabular}{|c|c|c|c|c|}
\hline Cost of treatment & Grade A & Grade B & Grade C & Grade D \\
\hline \multicolumn{5}{|c|}{ Cost of treatment per month (mean [SD]) } \\
\hline For patients & $14.33(6.52)$ & $14.87(6.76)$ & $23.48(19.98)$ & $23.62(10.78)$ \\
\hline For social security funds & $45.25(19.61)$ & $46.58(17.83)$ & $61.59(22.01)$ & $68.14(25.12)$ \\
\hline Total monthly cost & $59.67(25.47)$ & $61.46(22.18)$ & $82.18(30.27)$ & $91.75(34.36)$ \\
\hline \multicolumn{5}{|c|}{ Cost of treatment per year (mean [SD]) } \\
\hline For patients & |7|.98 (78.28) & I78.48 (8I.06) & $247.11(101.46)$ & $283.39(\mid 29.4 I)$ \\
\hline For social security funds & $543.04(235.29)$ & $559.00(213.97)$ & $739.04(264.10)$ & $817.66(301.48)$ \\
\hline Total annual cost & $715.01(305.87)$ & $737.48(266.18)$ & $986.14(363.26)$ & $\mathrm{I}, 101.05(4 \mid 2.29)$ \\
\hline
\end{tabular}

Abbreviations: GOLD, Global Initiative for Chronic Obstructive Lung Disease; SD, standard deviation. 
might receive lower doses of inhaled drugs, thus increasing the risk of complications and exacerbations, or they might receive more drugs than they need - according to their symptoms and disease severity - leading to unnecessary increase of treatment cost. This is confirmed by our previous study in which overtreatment was high in low-risk COPD patients. ${ }^{22}$ Moreover, it is common for these patients to visit their doctor only when an exacerbation occurs, and a possible hospitalization is required. In this case, patients have to be treated for the COPD exacerbation, and usually the maintenance treatment is not possible to be reassessed.

In our study, a significant proportion of patients were living in remote areas. These residents of rural areas usually face more barriers when accessing health care services, ${ }^{23}$ as long traveling distances and cost of transportation are serious difficulties that patients - who are often old - have to deal with. As a result, there are patients who prefer to buy the inhaled drugs by themselves, as the cost for traveling and visiting the doctor to prescribe their medication is higher than the actual cost of their treatment.

On the other hand, patients who visit their doctors to prescribe COPD medication have to face other challenges. Since doctors were obliged to prescribe generic medications, social security funds cover only $75 \%$ of the generic drug prescribed. This means that COPD patients have to bear the additional cost of the inhaled drugs they use or they have to change their medication with generic drugs, increasing the risk of poor adherence to treatment.

Souliotis et $\mathrm{al}^{24}$ had recently published a study based on prescriptions collected by the largest social insurance fund. According to this study, 174,357 patients received medication for COPD, which corresponds to a percentage of $1.75 \%$ of the total insured population. Given the reported prevalence of COPD in smaller samples in Greece (which ranged from $3.5 \%$ to $18.4 \%),{ }^{8,25-27}$ it seems that a smaller percentage of patients with COPD actually receives treatment through the reimbursement organization. This could be either due to poor adherence to treatment or because of the bad network of primary care physicians who prescribe medication in rural areas in Greece.

\section{Limitations}

Our study presents several limitations. Particularly, our study was designed to estimate the actual cost of maintenance treatment for patients with COPD and not to evaluate outcomes concerning the impact of financial crisis for COPD patients. It would be interesting if we could record the monthly income of COPD patients, but unfortunately it was not possible to collect this data. Moreover, we had not planned to ask patients about adherence to treatment, although we knew from our experience in outpatient department that during the last years, it is common for patients with COPD to reduce their inhaled medication for economic reasons.

\section{Conclusion}

Results of our study demonstrate that the cost of COPD medication in Greece is very high, in all disease stages. During economic crisis, patients with COPD have to spend a significant amount of their pensions for the treatment of COPD, while patients suffering from other chronic diseases also face greater difficulties. Many patients struggle to afford their medication because of the large income decrease, which may lead to poor adherence to treatment and thus increased costs due to disease complications.

\section{Disclosure}

The authors report no conflicts of interest in this work.

\section{References}

1. Kerasidou A, Kingori P, Legido-Quigley H. You have to keep fighting: maintaining healthcare services and professionalism on the frontline of austerity in Greece. Int $J$ Equity Health. 2016;15:118.

2. Kotrogianni F, Malli F, Gourgoulianis KI. Underdiagnosis of respiratory diseases during an economic downturn and the need for spirometry as a screening test. J Bras Pneumol. 2013;39(2):254-255.

3. Tsiligianni IG, Papadokostakis P, Prokopiadou D, Stefanaki I, Tsakountakis N, Lionis C. Impact of the financial crisis on adherence to treatment of a rural population in Crete, Greece. Qual Prim Care. 2014; 22(5):238-244.

4. Zavras D, Zavras AI, Kyriopoulos II, Kyriopoulos J. Economic crisis, austerity and unmet healthcare needs: the case of Greece. BMC Health Serv Res. 2016;16:309.

5. Kyriopoulos II, Zavras D, Skroumpelos A, Mylona K, Athanasakis K, Kyriopoulos J. Barriers in access to healthcare services for chronic patients in times of austerity: an empirical approach in Greece. Int $J$ Equity Health. 2014;13:54.

6. The Global Initiative for Chronic Obstructive Lung Disease (GOLD) Global strategy for the diagnosis, management and prevention of chronic obstructive pulmonary disease (Updated 2016). Available from: http:// www.goldcopd.org/. Accessed August 23, 2016.

7. World Health Organization. Chronic respiratory diseases. Chronic obstructive pulmonary disease (COPD) - Burden of COPD. Available from: http://www.who.int/respiratory/copd/burden/en/index.html. Accessed August 23, 2016.

8. Tzanakis N, Anagnostopoulou U, Filaditaki V, Christaki P, Siafakas N; COPD group of the Hellenic Thoracic Society. Prevalence of COPD in Greece. Chest. 2004;125(3):892-900.

9. Guarascio AJ, Ray SM, Finch CK, Self TH. The clinical and economic burden of chronic obstructive pulmonary disease in the USA Clinicoecon Outcomes Res. 2013;5:235-245.

10. European Lung White Book. The economic burden of lung disease. Available from: http://www.erswhitebook.org/chapters/the-economicburden-of-lung-disease/. Accessed August 24, 2016.

11. Geitona M, Hatzikou M, Steiropoulos P, Alexopoulos EC, Bouros D. The cost of COPD exacerbations: a university hospital-based study in Greece. Resp Med. 2011;105:402-409. 
12. Boland MR, Tsiachristas A, Kruis AL, Chavannes NH, Rutten-van Mölken MP. Are GOLD ABCD groups better associated with health status and costs than GOLD 1234 grades? A cross-sectional study. Prim Care Respir J. 2014;23(1):30-37.

13. Stafyla E, Kerenidi T, Gourgoulianis KI. Chronic obstructive pulmonary disease exacerbation frequency and severity. Int J Chron Obstruct Pulmon Dis. 2013;8:533-535.

14. Organisation for Economic Co-operation and Development (OECD). Pensions at a Glance 2015: OECD and G20 indicators, OECD Publishing, Paris. Available from: http://www.oecd.org/publications/oecdpensions-at-a-glance-19991363.htm. Accessed August 29, 2016.

15. Organisation for Economic Co-operation and Development (OECD). Pensions at a Glance 2007: Public Policies across OECD Countries, OECD Publishing, Paris. Available from: http://www.oecd-ilibrary. org/finance-and-investment/oecd-pensions-at-a-glance-2007_pension_glance-2007-en. Accessed November 15, 2016.

16. Skroumpelos A, Pavi E, Mylona K, Kyriopoulos J. The impact of economic crisis on chronic patients' self-rated health, health expenditures and health services utilization. Diseases. 2014;2:93-105.

17. Cutler DM, Everett W. Thinking outside the pillbox - medication adherence as a priority for health care reform. $N$ Engl J Med. 2010; 362(17):1553-1555.

18. Minas M, Verrou-Katsarou I, Mystridou P, Apostolidou E, Hatzoglou C, Gourgoulianis KI. Two-year mortality of patients with COPD in primary health care: an observational study. Int J Gen Med. 2012;5:815-822.

19. Mitsiki E, Bania E, Varounis C, Gourgoulianis KI, Alexopoulos EC. Characteristics of prevalent and new COPD cases in Greece: the GOLDEN study. Int J Chron Obst Pulmon Dis. 2015;10:1371-1382.
20. Piette JD, Rosland AM, Silveira MJ, Hayward R, McHorney CA. Medication cost problems among chronically ill adults in the US: did the financial crisis make a bad situation even worse? Patient Prefer Adherence. 2011;5:187-194.

21. Karamanoli E. Financial crisis harms respiratory health in Greece. Lancet Respir Med. 2013;1(7):511-512.

22. Papala M, Kerenidi N, Gourgoulianis KI. Everyday clinical practice and its relationship to 2010 and 2011 GOLD guideline recommendations for the management of COPD. Prim Care Respir J. 2013;22(3):362-364.

23. Shin H, Kim J. Differences in income-related inequality and horizontal inequity in ambulatory care use between rural and non-rural areas: using the 1998-2001 U.S. National Health Interview Survey data. Int J Equity Health. 2010;9:17.

24. Souliotis K, Kani C, Papageorgiou M, Lionis D, Gourgoulianis K. Using big data to assess prescribing patterns in Greece: the case of chronic obstructive pulmonary disease. PLoS One. 2016;11(5):e0154960.

25. Minas M, Koukosias N, Zintzaras E, Kostikas K, Gourgoulianis KI. Prevalence of chronic diseases and morbidity in primary health care in central Greece: an epidemiological study. BMC Health Serv Res. 2010;10:252.

26. Kourlaba G, Hillas G, Vassilakopoulos T, Maniadakis N. The disease burden of chronic obstructive pulmonary disease in Greece. Int JCOPD. 2016;11;2179-2189

27. Minas M, Hatzoglou C, Karetsi E, et al. COPD prevalence and the differences between newly and previously diagnosed COPD patients in a spirometry program. Prim Care Respir J. 2010;19(4):363-370.
International Journal of COPD

\section{Publish your work in this journal}

The International Journal of COPD is an international, peer-reviewed journal of therapeutics and pharmacology focusing on concise rapid reporting of clinical studies and reviews in COPD. Special focus is given to the pathophysiological processes underlying the disease, intervention programs, patient focused education, and self management protocols.

\section{Dovepress}

This journal is indexed on PubMed Central, MedLine and CAS. The manuscript management system is completely online and includes a very quick and fair peer-review system, which is all easy to use. Visit $\mathrm{http}: / /$ www.dovepress.com/testimonials.php to read real quotes from published authors. 